\title{
Opioids and the Immune System: Clinical Relevance
}

\author{
João Batista Santos Garcia, TSA, 1 , Mirlane Guimarães de Melo Cardoso ${ }^{2}$, Maria Cristina Dos-Santos ${ }^{3}$
}

Summary: Garcia JBS, Cardoso MGM, Dos-Santos MC - Opioids and the Immune System: Clinical Relevance.

Background and objectives: The increasing use of opioids for pain treatment is a reality in several countries and, therefore, unusual questions arise, such as the influence of opioids on immune responses. The present study aims to detail the immune response by exploring the influences of opiate effects on inflammatory response in experimental and clinical situations, as well as its importance in daily practice.

Content: After reviewing the articles published in journals indexed in Medline, we found that immune response has been generally described, especially regarding its cellular aspect. Following this approach, we identified the mechanisms of endogenous opioid release, modulation of immune response to exogenous opioids in acute and chronic pain, always ending with the clinical implications and applicability in routine care.

Conclusions: Although several studies point to an immunosuppressive effect of opioids, the clinical relevance of these observations remains uncertain and only serves as a prerequisite for further investigations in this area. Definitive recommendations for the use of opioids in various situations of clinical practice regarding the immunological consequences of these drugs still cannot be provided until the present moment.

Keywords: Analgesics, Opioids; Immune System; Pain.

@2012 Elsevier Editora Ltda. All rights reserved.

\section{INTRODUCTION}

Data from the literature show that opioids consumption has been growing significantly in recent decades. Many of its effects mainly in the organic systems are diverse and not completely known. Currently, we have identified a great interest in elucidating the influence of opioids on immune responses in management of patients with pain ${ }^{1}$.

Studies of interactions between the brain and immune system revealed bidirectional connections between the neural, endocrine, and immune systems. The central nervous system (CNS) regulates the immune system by neuronal and neuroendocrine pathways, whereas the immune system, which is innervated by sympathetic nervous system, signals the brain through humoral and neural pathways. Immune cells express receptors for hormones from various axes, numerous neurotransmitters and excitatory (glutamate, substance $P$, growth

Received from Universidade Federal do Maranhão (UFMA), Brazil.

1. PhD, Associate Professor, Department of Anesthesiology, Pain and Palliative Care, Universidade Federal do Maranhão (UFMA); Responsible for the Pain Clinic at Hospital Universitário da UFMA and Therapy Service Against Pain at Instituto Maranhense de Oncologia Aldenora Belo (IMOAB); President of the Brazilian Society for the Study of Pain Oncologia Aldenora Belo (IMOAB); President of the Brazilian Society for the Study of Pain
(SBED) in 2011-2012 (SBED) in 2011-2012

2. PhD, Associate Professor, Department of Pharmacology, Universidade Federal do Amazonas; Anesthesiologist; Certificate of Performance in the Area of Pain; Responsible for the Pain and Palliative Care Service, Fundação Centro de Controle de Oncologia do Amazonas

3. PhD Associate Professor, Department of Immunology, Department of Parasitology, 20082012 Coordinator of the Graduate Program in Basic and Applied Immunology (ICB / UFAM), Instituto de Ciências Biológicas, Universidade Federal do Amazonas

Submitted on August 28, 2011

Approved on January 19, 2012.

Correspondence to:

João Batista Santos Garcia, MD

Avenida São Marcos, Lote 4, Quadra C

Edifício Varandas do Atlântico, apto. 502

Ponta d'Areia

65077310 - São Luís, MA, Brazil.

E-mail:jbgarcia@uol.com.br factors) and inhibitory (opioids, gamma-aminobutyric acid [GABA] acid, and glycine) biochemical mediators ${ }^{1,2}$.

This article aims to detail the immune response by exploring the influences of opiate effects on the inflammatory response in experimental and clinical situations, as well as its importance for daily practice.

\section{OVERVIEW OF IMMUNE RESPONSE}

The immune response is performed by cooperation of components from the innate immune system (IIS) and adaptive immune system (AIS). IIS is the first line of defense because it quickly recognizes the pathogen due to the presence of pattern recognition receptors (PRR) present in plasma membranes, cytosol, endosome, lysosome, or endolysosome of immune cells, which bind to pathogen structures called pathogen-associated molecular patterns (PAMP) ${ }^{2,3,4}$, triggering the inflammatory response and directing the adaptive immune response. The innate immunity cells are not divided, do not form clones, and do not produce memory cells. However, a form of immune memory has been attributed to some cells of innate immunity, such as mast cells ${ }^{5}$ and natural killer cells (NK) ${ }^{6}$.

When the body is infected, pathogens are recognized by epithelial dendritic cells, which have the function of presenting antigens to naive T lymphocytes of the AIS in secondary lymphoid organs. Phagocytic cells, such as macrophages, neutrophils, and dendritic cells, have PRR that bind directly to its respective PAMP present in the walls of pathogens, or may recognize it indirectly by binding its receptors membrane with serum or saliva proteins, the soluble PRR (C-reactive protein, mannose binding protein [MBL]) or opsonins (C3b, C4b, MBL - Complement System components) that have bound to the pathogen. Macrophages, mast cells, dendritic cells, T lympho- 
cytes $\gamma: \Delta$, neutrophils, mucosal epithelial cells and endothelial cells, among others, express another family of receptors that interact with PAMP, called Toll-like receptor (TLR), which are involved with intracellular signaling for transcription of cytokines and other molecules that induce immune and inflammatory response. These receptors are type I transmembrane proteins consisting of ectodomains containing a leucine rich region that mediates PAMP recognition, a transmembrane domain, and an intracellular Toll/interleukin-1 receptor (TIR) domain responsible for translating signals.

Currently, 12 functional Toll-like receptors have been described for mice and 10 for humans. These receptors may be found expressed in cell membrane (TLR1, 2, 4, 5, and 6) for recognizing microbial wall components, such as lipids, lipoproteins, and proteins, or present in intracellular vesicles (TLR3, 7, 8, and 9), such as endosome, lysosome, and endoplasmic reticulum endolysosome to detect nucleic acids from pathogen degradation. In dendritic cell, the interaction of Toll-like receptors with corresponding PAMP triggers a series of reactions, such as production of PRR involved in phagocytosis, production of proinflammatory cytokines (or type I interferon production), expression of costimulatory molecules on membrane, and maturation of these naive dendritic cells. Therefore, when this interaction occurs, it not only initiates the acute inflammatory response but also targets a more specific answer - from AIS - against invading pathogen ${ }^{2,4}$.

Activation of AIS occurs with the invading agent presentation by dendritic cells to naïve T-helper (Th) cells. Macrophages, B-lymphocytes, $T \gamma: \Delta$ lymphocytes and, occasionally, epithelial cells have the function of presenting the antigen to the effector T-lymphocytes. Then, resident dendritic cells capture and involve the invading agent and, subsequently, migrate to secondary lymphoid organs. In this route, dendritic cells start processing the pathogenic peptides in its cytoplasmic vesicles and protein synthesis of the major histocompatibility complex Class II (MHC or MHC; or HLA in human) in endoplasmic reticulum. Also in cytoplasm, vesicle fusion occurs, which contains processed peptides with MHC class II molecules. At that moment, peptides are embedded in the groove of MHC II, forming the MHC II-peptide complexes that will be exteriorized on cell membrane, so that peptides are recognized by the corresponding CD4+ T lymphocytes. The naïve TCD4+ (Th0) lymphocytes, which recognize the peptides in the groove of $\mathrm{MHC}$ class II, after receiving the stimulation of the membrane costimulatory molecules and influence of cytokines, undergo clonal expansion and differentiate into effector cells Th1, Th2 or Th17, in the presence of IL-12 and IFN- ; IL-4 and IL-2; or TGF- $\beta$, IL-6, and IL-21, respectively. This differentiation depends on the invading agent and on these cytokines, released by dendritic cells or present in the microenvironment where antigen presentation occurred 7 .

On membrane surface, B-lymphocytes express immunoglobulin that act as antigens receptors. Therefore, each B-lymphocyte, similar to T-lymphocytes, builds on somatic lineage its own site of the epitope recognition, which is present in all immunoglobulin produced by B cells derived from the same clone. The B lymphocytes, present in peripheral lymphoid or- gans, which recognize the epitopes of invading agent, or on toxin structure, or on the surface of follicular dendritic cells and receive $T$ helper lymphocytes stimulation, also undergo clonal expansion. The produced cells differentiate into plasma cells, producing and secreting immunoglobulins, which help to neutralize and eliminate the invader ${ }^{7}$.

\section{ENDOGENOUS OPIOID AND THE IMMUNE SYSTEM}

\section{Peripheral opioid receptors}

A few years ago, studies began to show that opioids not only had an action on brain and spinal cord receptors but also in peripheral sensory neurons, leading to a close examination of the mechanism of action of these substances outside the central nervous system (CNS) ${ }^{8,9}$.

Inflammatory pain stimulation in peripheral tissues is considered a trigger for regulation of opioid receptors in adult sensory neurons. The inflammatory response is accompanied by the proliferation of opioid receptors in peripheral sensory terminals through the rupture of a perineural barrier that facilitates access to these substances and its receptors, and at low $\mathrm{pH}$, it may increase the agonist effect by interfering with the interaction of opioid receptors with $G$ proteins ${ }^{10,11}$ (responsible for signaling these drugs). During inflammation, there is an upward adjustment of opioid receptors in the spinal cord dorsal horn, and, consequently, increased axonal transport of receptors to the periphery stimulated by cytokines (IL-1, IL-6, and TNF- $\alpha$ ) and neuronal growth factor from the inflammation site. Cytokines are proteins produced and released by all cells, except erythrocytes, which have pleiotropic action and act on multiple target cells with multiple overlapping biological effects by its binding to specific high-affinity receptors present in the cell membrane. Cytokines then regulate growth and proliferation of glial cells, modulate the activity of endogenous opioid peptides, and activate the hypothalamic-pituitary-adrenal (HPA) axis. This whole process results in a high density of opioid receptors in peripheral nerve terminals, contributing to the antinociceptive efficacy of opiates in inflamed tissues. In the initial stages (first hours) of inflammatory response, there is a contribution of both central and peripheral opioid receptors; however, in later stages (several days), endogenous analgesia is predominantly mediated by peripheral receptors, thus becoming more prevalent with the duration and intensity of inflammation 8,12 .

\section{Endogenous opioids}

The discovery of opioid receptors in sensory neurons resulted in the detection of endogenous peptide ligand in tissues with inflammatory processes. There are currently three known families of peptides, which are expressed and regulated on granulocytes, macrophages, and lymphocytes, both in rodents and in humans. Each family comes from a distinct gene and one of the three protein precursors: proopiomelanocortin 
(POMC), pro-enkephalin (Penk), and prodynorphin, which are processed to endorphin, enkephalin, and dynorphin, respectively. These peptides exhibit different affinities for opioid receptors $\mu$ (endorphins and enkephalins), $\Delta$ (enkephalins and endorphins), and (dynorphin) and are reported in various immune cells ${ }^{13}$.

It became clear from animal models that - concomitantly with the pro-inflammatory and pro-nociceptive effects mediated by a myriad of mediators released in injured tissues - there are endogenous mechanisms that counter-regulate pain and inflammation. Consistently, in experiments with bone cancer, as well as in humans undergoing knee surgeries, local injection of opioid antagonists in inflammation sites caused pain exacerbation ${ }^{14}$. This strongly indicates that endogenous opioid peptides are released continuously and have an action to combat pain.

Studies in rats demonstrated that there is a co-expression of chemokine receptors and bradykinin on leukocytes attracted and migrated toward the site of tissue lesion, which contain endogenous opioids. When there is a depletion of granulocytes, immunosuppression, or blockage of chemokines and neurokinins there is also a significant reduction of antinociception 15-17.

By contrast, there is improved analgesia when allogeneic lymphocytes or polymorphonuclear leukocytes (PMN) is transferred in case of immunosuppression 18,19. Other known sites of endogenous opioid production are the adrenal, pituitary, and afferent neurons, but without the same relevance of the producing cells from inflammation sites ${ }^{20}$.

\section{Clinical implications}

Opioid receptors are present at peripheral sensory neuron terminals and are capable of producing analgesia. Opioid peptides are produced by synovial cells, mast cells, lymphocytes, neutrophils, and monocytes migrating to sites of injury ${ }^{21,22}$. Intra-articular blockade of receptors in human knees, with local administration of naloxone, resulted in significant increase in post-operative pain ${ }^{23}$. Taken together, these data suggest that in stressful situations opioids are tonically released within inflamed tissue and activate peripheral opioid receptors that can alleviate pain. This constitutes a new concept of intrinsic control of pain involving mechanisms traditionally used by immune cells to respond to aggressors. It also provides new questions regarding pain associated with an impaired immune system, such as patients with cancer and other diseases. The increased production, migration, and release of endogenous opioids from immune cells may provide a novel option for the development of agents that act peripherally and are devoid of the undesirable central effects of exogenous opioids.

\section{EXOGENOUS OPIOID AND THE IMMUNE SYSTEM}

Administration of opioids may affect the immune system in several ways. However, there are many questions surrounding this phenomenon, such as what is the best way to measure it; how valuable are tests with the proliferation and functionality of lymphocytes and other immune cells; or with the assessment of communication between cells; or with the expression of receptors involved in recognition and presentation of antigens; or regarding the balance of cytokines, in addition to the need of understanding what is the biological significance of such changes. Moreover, most studies on the issue occur in organisms not subjected to pain, which can alter the interpretation of results ${ }^{24}$.

\section{Mechanisms of opioid-induced immunomodulation}

There are two different mechanisms of immunemodulation by opioids (in vitro and in vivo). In vitro experiments have shown that morphine and other opioids impair the phagocytic and chemotactic function of neutrophils and monocytes, reduce the effector response of $B$ and $T$ lymphocytes, and increase lymphocyte and phagocytic cell apoptosis ${ }^{25-27}$. In vivo studies have also shown an indirect effect of opioids, especially morphine, involving reduction of NK cell function and lymphocyte proliferative activity in response to mitogens, suppression of inflammatory cytokines, and activation of the sympathetic nervous system that promotes high levels of noradrenaline and is related to immunosuppression ${ }^{28,29}$. These effects appear to be related to down regulation of protein kinase $\mathrm{C}$, actions mediated by somatostatin, engagement of pro-apoptotic enzymes, and change in the release of nitric oxide ${ }^{30-33}$.

\section{Acute administration of opioids and the immune system}

Many animal studies have shown that morphine acutely administered has immunosuppressant effect, even at varying doses ranging from 5 to $50 \mathrm{mg} \cdot \mathrm{kg}^{-1}{ }^{34-38}$. There are fewer studies with humans, but the results are consistent with immunosuppression. However, compared to other opioids this picture changes, as the effect with fentanyl is transient and non-existent with buprenorphine and tramadol ${ }^{39,40}$. Synthetic opioids exhibit this effect possible due to the weaker interaction with opioid receptors present on leukocytes.

An important aspect of acute cases is the fact that the painful stimulus itself is related to immunosuppression (by the release of cortisol), changing the recovery of aggressive events as surgical procedures. Patients in postoperative recovery have significant reduction in lymphocyte proliferative activity, cell-mediated immunity, and changes in the balance of $T$ lymphocytes ${ }^{41,42}$. These events are higher the major the surgery and pain severity. Therefore, the use of opioids may be considered beneficial.

In a study assessing the presence of pneumonia in elderly patients undergoing myocardial revascularization, multivariate analysis showed an association between disease and high doses of morphine, although the sample was small and the confidence interval wide ${ }^{43}$. Other authors observed, however, that small doses of intravenous morphine $\left(15 \mathrm{mcg} \cdot \mathrm{kg}^{-1} \cdot \mathrm{h}^{-1}\right)$ protected alcoholic patients from developing pneumonia after 
cancer operations ${ }^{44}$. These studies clearly show contradictory data regarding the immune action of opioids during perioperative period.

\section{Chronic administration of opioids and the immune system}

In animals, the study of chronic use of opioids is performed by repeated injections at various periods of time or implantable devices, commonly used for tolerance and dependence evaluation. Daily injections of larger doses of morphine (30$50 \mathrm{mg} \cdot \mathrm{kg}^{-1}$ ) suppressed the activity of cells NK type (ACLNK), which was not observed in controls rats ${ }^{45}$. In another study, subcutaneous administration of morphine ( $40 \mathrm{mg} \cdot \mathrm{kg}^{-1}$ ) over 24 hours resulted in impaired activity of macrophages and, after three days, bacteremia occurred, as well as bacterial growth in peritoneal fluid, liver, spleen, kidneys, heart, and lung. These effects were blocked when naloxone, a pure opioid antagonist, was administered before each morphine dose, which implies an opioid receptor-dependent mechanism ${ }^{46}$. Other authors, using similar animal models, suggest that the host becomes more susceptible to some types of infections, including metastatic spread of neoplastic diseases 47,48 . However, in an interesting work of mice with significant hyperalgesia associated with melanoma, pretreatment with morphine significantly reduced the spread of tumor metastasis, showing a beneficial effect of morphine for treating cancer pain 49 .

In humans, a study conducted with morphine doses ranging from $90-150 \mathrm{mg}$ for 36 to 60 hours resulted in significant suppression of antibody-dependent cellular cytotoxicity (ADCC) compared to controls; however, regarding ACLNK no difference was seen between groups ${ }^{50}$.

We found no studies evaluating the role of exposure to opioids, with respect to worsening of indicators in infected individuals who are in intensive care units ${ }^{51}$. In hospitalized burn patients, the authors found some type of impairment, such as reduced time to first infection; however, this result may not be generalized due to the difficulty of replicating the study design and great possibility of bias 52 .

In the NEOPAIN study, a large number of premature patients intubated on mechanical ventilation were randomized to receive liberal doses of morphine versus minimal doses. The study objective was not to examine infectious complications but other complications such as ventricular hemorrhage and death, and the authors reported no difference between groups regarding the onset of infection ${ }^{53}$.

\section{Clinical relevance}

Although several studies point to an immunosuppressive effect of opioids, the clinical relevance of these observations remains uncertain and only serves as a prerequisite for further investigations in this area. Definitive recommendations for the use of opioids in various situations of clinical practice in relation to the immunological consequences of these drugs may not be provided yet. Because each substance seems to have a different effect, further studies with other opioids, in addition to morphine, should be performed. Still, specific subpopulations, such as immunocompromised and critically ill patients, should also be investigated. 


\section{REFERENCES}

1. Sacerdote $P$ - Opioids and the immune system. Palliat Med, 2006;20:9-15.

2. Akira $\mathrm{S}$, Uematsu $\mathrm{S}$, Takeuchi $\mathrm{O}$ - Pathogen recognition and innate immunity. Cell 2006;124:783-801. 
3. Yoneyama M, Fujita T - RNA recognition and signal transduction by RIG-I-like receptors. Immunol Rev, 2009;227:54-65.

4. Kawai T, Akira $S$ - The role of pattern-recognition receptors in innate immunity: update on Toll-like receptors. Nature Immunology, 2010;11(5):373-384.

5. Abraham SN, St. John AL - Mast cell-orchestrated immunity to pathogens. Nature Reviews Immunology, 2010;10(6):440-452.

6. Paust $\mathrm{S}$, von Andrian $\mathrm{UH}-$ Natural killer cell memory. Nature Immunoly, 2011;12(6):500-508.

7. Zhu J, Yamane H, Paul W E - Differentiation of effector CD4 T cell populations. Annu Rev Immunol, 2010;28:445-489.

8. Stein $\mathrm{C}$, Schafer M, Machelska $\mathrm{H}$ - Attacking pain at its source: new perspectives on opioids. Nat Med, 2003;9:1003-1008.

9. Stein C, Zollner C - Opioids and sensory nerves. In Pharmacology of Sensory Nerves, Handbook of Experimental Pharmacology. Edited by Canning BJ, Spina D. Springer, Heidelberg; 2009.

10. Vetter I, Kapitzke D, Hermanussen S, Monteith GR, Cabot PJ - The effects of $\mathrm{pH}$ on beta-endorphin and morphine inhibition of calcium transients in dorsal root ganglion neurons. J Pain, 2006;7:488-499.

11. Mousa SA, Shakibaei M, Sitte N, Schafer M, Stein C - Subcellular pathways of beta-endorphin synthesis, processing, and release from immunocytes in inflammatory pain. Endocrinology, 2004;145:13311341.

12. Machelska H, Schopohl JK, Mousa SA, Labuz D, Schafer M, Stein C - Different mechanisms of intrinsic pain inhibition in early and late inflammation. J Neuroimmunol, 2003;141:30-39.

13. Hollt $\mathrm{V}$ - Opioid peptide processing and receptor selectivity. Annu Rev Pharmacol Toxicol, 1986;26:59-77.

14. Stein C, Lang JL - Peripheral mechanisms of opioid analgesia. Curr Opin in Pharmacol, 2009;9:3-8.

15. Brack A, Rittner HL, Machelska H, Leder K, Mousa SA, Schafer $\mathrm{M}$, Stein $\mathrm{C}$ - Control of inflammatory pain by chemokine-mediated recruitment of opioid-containing polymorphonuclear cells. Pain, 2004;112:229-238.

16. Rittner HL, Lux C, Labuz D, Mousa SA, Schafer M, Stein C, Brack A - Neurokinin-1 receptor antagonists inhibit the recruitment of opioidcontaining leukocytes and impair peripheral antinociception. Anesthesiology, 2007;107:1009-1017.

17. Machelska H, Mousa SA, Brack A et al. - Opioid control of inflammatory pain regulated by intercellular adhesion molecule-1. J Neurosci, 2002;22:5588-5596.

18. Hermanussen S, Do M, Cabot PJ - Reduction of beta-endorphincontaining immune cells in inflamed paw tissue corresponds with a reduction in immune-derived antinociception: reversible by donor activated lymphocytes. Anesth Analg, 2004;98:723-729.

19. Rittner HL, Labuz D, Schaefer $M$ et al. - Pain control by CXCR2 ligands through $\mathrm{Ca} 2+-$ regulated release of opioid peptides from polymorphonuclear cells. FASEB J, 2006;20:2627-2629.

20. Machelska $\mathrm{H}$, Stein $\mathrm{C}-$ Immune mechanisms in pain control. Anesth Analg, 2002;95:1002-1008.

21. Stein C, Pfluger M, Yassouridis A et al. - No tolerance to peripheral morphine analgesia in presence of opioid expression in inflamed synovia. J Clin Invest, 1996;98:793-799.

22. Stein C, Comisel K, Haimerl E et al. - Analgesic effect of intraarticular morphine after arthroscopic knee surgery. N Engl J Med, 1991;325:1123-1126.

23. Stein $\mathrm{C}$, Hassan AHS, Lehrberger $\mathrm{K}$ et al. - Local analgesic effect of endogenous opioid peptides. Lancet, 1993;342:321-324.

24. Page GG - Immunologic effects of opioids in the presence or absence of pain. J Pain Symp Manag 2005;29:S25-31.

25. Singhal $\mathrm{P}$, Kapasi A, Reddy K, Franki N - Opiates promote $\mathrm{T}$ cell apoptosis through JNK and caspase pathway. Adv Exp Med Biol, 2002;493:127-135

26. Singhal PC, Sharma P, Kapasi AA et al. - Morphine enhances macrophage apoptosis. J Immunol, 1998;160:1886-1893.

27. Singhal PC, Kapasi AA, Reddy K et al. - Morphine promotes apoptosis in Jurkat cells. J Leukoc Biol, 1999;66:650-658.

28. Mellon RD, Bayer BM - Evidence for central opioid receptors in the immunomodulatory effects of morphine: review of potential mechanism(s) of action. J Neuroimmunol, 1998;83:19-28.
29. Flores LR, Dretchen KL, Bayer BM - Potential role of the autonomic nervous system in the immunosuppressive effects of acute morphine administration. Eur J Pharmacol, 1996;318:437-446.

30. McCarthy L, Wetzel M, Sliker JK et al. - Opioids, opioid receptors, and the immune response. Drug Alcohol Depend, 2001;62:111-123.

31. Sacerdote $P$, Manfredi B, Mantegazza P, Panerai AE - Antinociceptive and immunosuppressive effects of opiate drugs: a structure-related activity study. Br J Pharmacol, 1997;121:834-840.

32. Schneemilch CE, Schilling T, Bank U - Effects of general anaesthesia on inflammation. Best Pract Res Clin Anaesthesiol, 2004;18:493507.

33. Walters I - Opioids and immunosuppression: clinical relevance. Anaesthetist, 2003;52:442-452.

34. Shavit Y, Terman GW, Lewis JW et al. - Effects of footshock stress and morphine on natural killer lymphocytes in rats: studies of tolerance and crosstolerance. Brain Res, 1986;372:382-385.

35. Shavit $Y$, Martin FC, Yirmiya R et al. - Effects of single administration of morphine or footshock stress on natural killer cell cytotoxicity. Brain Behavlmmun, 1987;1:318-328.

36. Coussons-Read ME, Giese S - Acute morphine treatment alters cellular immune function in the lungs of healthy rats. Int Immunopharmacol, 2001;1:1571-1581.

37. Flores LR, Wahl SM, Bayer BM - Mechanisms of morphine-induced immunosuppression: Effect of acute morphine administration on lymphocyte trafficking. J Pharmacol Exp Ther, 1995;272:1246-1251.

38. Lysle DT, Coussons ME, Watts VJ et al. - Morphine-induced alterations of immune status: dose dependency, compartment specificity and antagonism by naltrexone. J Pharmacol Exp Ther, 1993;265:1071 1078.

39. Bilfinger TV, Fimiani C, Stefano GB - Morphine's immunoregulatory actions are not shared by fentanyl. Int J Cardiol, 1998;64(Suppl 1):S61-S66.

40. Martucci C, Panerai AE, Sacerdote R - Chronic fentany! or buprenorphine infusion in the mouse: similar analgesic profile but different effects on immune responses. Pain, 2004;110:385-392.

41. Decker $D$, Schondorf $M$, Bidlingmaier $F$ et al. - Surgical stress induces a shift in the type-1/type-2 T-helper cell balance, suggesting downregulation of cell-mediated and up-regulation of antibodymediated immunity commensurate to trauma. Surgery, 1996;119:316-325.

42. Schietroma M, Carlei F, Lezoche E et al. - Evaluation of immune response in patients after open or laparoscopic cholecystectomy. Hepatogastroenterol, 2001;48:642-646.

43. El Solh AA, Bhora M, Pineda L, Dhillon R - Nosocomial pneumonia in elderly patients following cardiac surgery. Resp Med, 2006;100:729736.

44. Spies C, Eggers V, Szabo G - Intervention at the level at the neuroendocrine-immune axis and postoperative pneumonia rate in long-term alcoholics. Am J Respir Crit Care Med, 2006;100:729-736.

45. Shavit $Y$, Terman GW, Lewis JW et al. - Effects of footshock stress and morphine on natural killer lymphocytes in rats: studies of tolerance and crosstolerance. Brain Res, 1986;372:382-385.

46. Bhaskaran M, Reddy K, Sharma S et al. - Morphine-induced degradation of the host defense barrier: Role of macrophage injury. J Infect Dis, 2001;184:1524-1531.

47. De Waal EJ, Van Der Laan JW, Van Loveren H - Effects of prolonged exposure to morphine and methadone on in vivo parameters of immune function in rats. Toxicol, 1998;129:201-210.

48. Coussons-Read ME, Daniels M, Gilmour MI - Morphine reduces pulmonary inflammation in response to influenza infection. Life Sci, 1999; 65:1141-1152.

49. Sasamura $T$, Nakamura $S$, lida $Y$ et al. - Morphine analgesia suppresses tumor growthand metastasis in a mouse model of cance pain produced by orthotopic tumor inoculation. Eur J Pharmacol, 2002;441:185-191.

50. Yeager MP, Yu CT, Campbell AS et al. - Effect of morphine and betaendorphin on human $\mathrm{Fc}$ receptor-dependent and natural killer cell functions. Clin Immunol Immunopathol, 1992;62:336-343.

51. Weinert CR, Kethireddy S, Roy S - Opioids and infections in the intensive care unit should clinicians and patients be concerned? J Neuroimmune Pharmacol, 2008; 3:218-229. 
52. Schwacha MG, McGwin Jr. G, Hutchinson CB, Cross JM, Maclennan PA, Rue LW - The contribution of opiate analgesics to the development of infectious complications in burn patients. Am J Surg, 2006;192:82-86

53. Anand KJ, Hall RW, Desai $\mathrm{N}$ et al. - Effects of morphine analgesia in ventilated preterm neonates: primary outcomes from the Neopain randomized trial. Lancet, 2004;363:1673-1682. 